\title{
Características Morfológicas e Índice de Área Foliar do Capim-Tanzânia (Panicum maximum Jacq. cv. Tanzânia-1) Manejado em Diferentes Alturas, sob Pastejo ${ }^{1}$
}

\author{
Fabíola Cristine de Almeida Rêgo ${ }^{2}$, Ulysses Cecato ${ }^{3}$, Marcos Weber do Canto 4 , Elias Nunes Martins ${ }^{3}$, \\ Geraldo Tadeu dos Santos ${ }^{3}$, Clovenilson Perissato Cano ${ }^{5}$, Maurício Peternelli ${ }^{6}$
}

RESUMO - O objetivo do trabalho foi avaliar o efeito de diferentes alturas $(24,26,43,45,52,62,73$ e $78 \mathrm{~cm})$ do pasto e diferentes períodos de coleta $(28,56,84$ dias), sobre a densidade de perfilhos aéreos e basais, peso e diâmetro de perfilhos basais, índice de área foliar (IAF), altura do meristema apical, número de nós e comprimento de entrenós em pastagem de capim-Tanzânia (Panicum maximum Jacq. cv. Tanzânia - 1). Foram utilizados novilhos da raça Nelore em regime de pastejo com carga animal variável, por meio da técnica "put and take". O delineamento experimental utilizado foi inteiramente casualizado com duas repetições. A densidade de perfilhos aéreos, o peso, o diâmetro, o número de nós e o comprimento de entrenós de perfilhos basais , a altura de meristema apical e o IAF aumentaram com os incrementos da altura de manejo das plantas. O perfilhamento basal não foi alterado em função das alturas de manejo, mas reduziu no decorrer do experimento, assim como o perfilhamento aéreo. As variáveis número de nós, comprimento de entrenós, altura do meristema apical e IAF apresentaram comportamento quadrático, em função do período de coleta.

Palavras-chave: altura do pasto, comprimento de entrenós, meristema apical, número de nós, perfilhamento

\section{Morphological Characteristics and Leaf Area Index of Tanzaniagrass (Panicum maximum Jacq. cv. Tanzânia - 1), Managed in Different Sward Heights, under Grazing}

\begin{abstract}
The effect of different sward heights (24, 26, 43, 45, 52, 62, 73 and $78 \mathrm{~cm})$ and different sampling periods (28, 56, 84 days), on basal and aerial tiller density, weight and diameter of basal tillers, leaf area index (LAI), meristem apical height, node number and internode length basal tiller in Tanzaniagrass (Panicum maximum Jacq. cv. Tanzânia - 1) is provided. Nelore steers were used in grazing, with variable stocking rates, using put and take techniques. The experimental design was completely randomized, with two replications. Aerial tiller density, weight, diameter, node number and internode length basal tiller, apical meristem height and leaf area index increased according to the higher sward management height. Basal tillering was not affected by sward management heights, but decreased during the experiment. Aerial tiller had a similar behavior. Node number, internode length, apical meristem height and LAI had a negative quadratic behavior, according to the sample collection period.
\end{abstract}

Key Words: apical meristem, node number, internode length, sward height, tillering

\section{Introdução}

As características morfológicas das plantas definem a organização espacial das mesmas, influenciam na palatabilidade e facilidade de apreensão pelos herbívoros e afetam o crescimento, logo após a desfolha. A perenidade e a recuperação de plantas após o corte ou pastejo dá-se pela contínua substituição de perfilhos (Briske, 1991).

Além da capacidade de perfilhar, outros fatores influenciam na recuperação das plantas após o corte ou pastejo, como: a sobrevivência dos meristemas apicais, o uso dos carboidratos de reserva, a área foliar remanescente e as condições do meio ambiente (Gomide \& Zago, 1980; Monteiro et al., 1996). Entretanto, o perfilhamento depende das condições internas e externas à planta, sendo regulado, principalmente, pelo genótipo, balanço hormonal, florescimento, luz, temperatura, água, nutrição mineral e manejo (Langer, 1979).

A quantidade de perfilhos produzidos e a duração do processo variam entre espécies, sendo que algumas perfilham abundantemente e, outras, espaçadamente (Gomide \& Zago, 1980; Nascimento et al., 1980). O perfilhamento também apresenta diferenças entre cultivares da mesma espécie, conforme Herling et al.

\footnotetext{
1 Parte da dissertação do primeiro autor, apresentada à Universidade Estadual de Maringá, financiado pela CAPES.

2,5 Alunos do curso de Doutorado e Mestrado em Zootecnia da UEM. E.mail: fabiolarego@hotmail.com

3 Professores do Departamento de Zootecnia - UEM, bolsistas do CNPq. E.mail: ucecato@uem.br

4 Professor do Departamento de Zootecnia - UEM.

6 Aluno do curso de Mestrado em Zootecnia da USP-SP.
} 
(1995), que averiguaram maior perfilhamento na cultivar colonião, em relação à Centenário, dentro do gênero Panicum sp.

Outro fator que intensifica o processo de perfilhamento nas gramíneas é a eliminação do meristema apical, cessando, assim, a dominância que este exerce sobre as outras gemas da planta, estimulando o perfilhamento lateral e contribuindo para a recuperação e o aumento na produção da planta (Langer, 1979). Além disso, o perfilhamento lateral induz à maior abertura das touceiras, melhorando a ocupação do espaço aéreo e a interceptação de luz (Monteiro et al., 1996).

A área foliar remanescente, após o corte ou pastejo, é de grande importância para a rebrota, pois afeta, através da fotossíntese, a velocidade de recuperação do pasto. O índice de área foliar (IAF) define-se como a área ocupada por folhas, em relação à área de solo ocupada pela planta (Brougham, 1956). A freqüência e a intensidade de desfolha afetam o índice de área foliar remanescente após corte ou pastejo.

De acordo com Humphreys (1991), para Panicum maximum, a faixa de IAF ótimo situa-se entre 3 e 5 , sendo que, abaixo destes valores, a taxa de crescimento do pasto é reduzida, mas, ao alcançar o índice ótimo, estabiliza-se ou reduz, devido ao sombreamento da porção inferior da planta.

Alguns trabalhos exploram a possibilidade de se empregar o número de perfilhos por unidade de área como índice de produção de uma pastagem (Langer, 1979). Segundo Silsbury (1966), a produção de matéria seca das gramíneas, especialmente as não rizomatosas, pode ser considerada como decorrência do aumento em número e peso de perfilhos.

No pasto, as características relacionadas aos perfilhos variam em função do manejo. Almeida et al. (2000) observaram tendência de redução no número de perfilhos e aumento no peso destes à medida em que aumentou a oferta de forragem. Nesse mesmo trabalho, houve redução na altura do meristema apical, no número de nós e no comprimento de entrenós, com o decréscimo da oferta de forragem, evidenciando a plasticidade da planta.

O objetivo do presente trabalho foi avaliar a densidade de perfilhos aéreos e basais, o diâmetro e o peso de perfilhos basais, o número de nós e comprimento de entrenós, a altura do meristema apical e o IAF de uma pastagem de capim-Tanzânia (Panicum maximum Jacq. cv. Tanzânia 1) submetida a diferentes alturas do pasto, sob pastejo.

\section{Material e Métodos}

O experimento foi conduzido na Fazenda Nossa Senhora Aparecida, no município de Astorga, localizado na região Noroeste do Paraná, no período que compreendeu janeiro a maio de 1999.

O clima da região é classificado como subtropical úmido, mesotérmico, com verões quentes, geadas pouco freqüentes, com concentração de chuvas nos meses de verão (Cfa) (Corrêa, 1996). As coordenadas geográficas do município são $51^{\circ} 57^{\prime}$ de longitude, $23^{\circ} 25^{\prime}$ de latitude e $542 \mathrm{~m}$ de altitude. Os dados médios de temperatura e precipitação pluviométrica, ao longo do experimento são apresentados na Figura 1.

O solo da área experimental correspondeu a um Latossolo Vermelho Escuro, com a seguinte composição química: $\mathrm{pH}(\mathrm{H} 2 \mathrm{O})=6,9 ; \mathrm{Al}+++=0,0 \mathrm{cmolc} / \mathrm{dm}^{3}$; $\mathrm{H}++\mathrm{Al}+++=3,13 \mathrm{cmolc} / \mathrm{dm}^{3} ; \mathrm{Ca}+++\mathrm{Mg}++=7,16$ $\left(\mathrm{cmolc} / \mathrm{dm}^{3}\right) ; \mathrm{Ca}++=5,88 \mathrm{cmolc} / \mathrm{dm}^{3} ; \mathrm{K}+=0,6 \mathrm{cmolc} / \mathrm{dm}^{3}$; $\mathrm{P}=3,0 \mathrm{mg} / \mathrm{dm}^{3} ; \mathrm{C}=15,96 \mathrm{~g} / \mathrm{dm}^{3}$.

Realizou-se a adubação, conforme análise química de solo e segundo as recomendações da Comissão de Fertilidade do Solo-RS/SC (1995). Por ocasião do plantio, utilizaram-se $300 \mathrm{~kg} / \mathrm{ha} \mathrm{da}$ fórmula 0-20-20 (NPK) e mais $600 \mathrm{~kg} / \mathrm{ha} \mathrm{de}$ superfosfato simples, que corresponderam a doses de $180 \mathrm{~kg} / \mathrm{ha}$ de $\mathrm{P}_{2} \mathrm{O}_{5}$ e $60 \mathrm{~kg} / \mathrm{ha}$ de $\mathrm{K}_{2} \mathrm{O}$, respectivamente. A adubação nitrogenada foi parcelada em quatro vezes, sendo: 40, 100, $80 \mathrm{e}$ $30 \mathrm{~kg} / \mathrm{ha}$ aplicados a lanço, em 13/11/1998, 21/01, 27/02 e 10/03/1999.

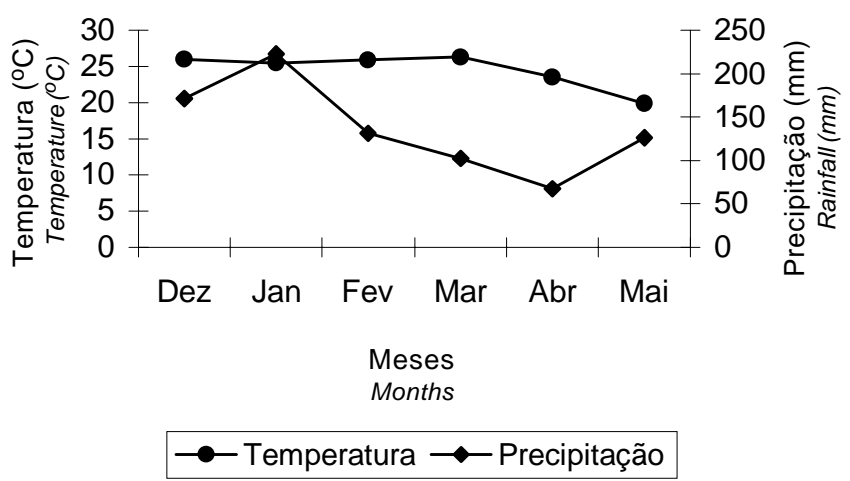

Figura 1 - Média mensal temperatura e precipitação pluviométrica durante o período experimental.

Figure 1 - Monthly mean temperature and rainfall during the experimental period. 
A semeadura do capim-Tanzânia (Panicum maximum Jacq. cv. Tanzânia1) foi feita a lanço em setembro de 1998, utilizando-se $12 \mathrm{~kg} /$ ha de sementes, com Valor Cultural de $30 \%$.

A área experimental consistiu de oito piquetes formados pelo capim-Tanzânia, de aproximadamente 1,0 ha cada, separados por cerca de cinco fios e uma área adicional com a mesma gramínea forrageira para mantença dos animais reguladores do pasto. Em todos os piquetes, foram instalados cochos de sal e reservatório de água (1000 litros) para os animais.

Foram utilizados quatro tratamentos, alturas do pasto, e duas repetições, em um delineamento inteiramente casualizado, sendo as alturas iniciais pretendidas: 20, 40, 60 e $80 \mathrm{~cm}$. Entretanto, as alturas médias reais estimadas para as duas repetições foram: $24 \mathrm{e}$ $26 \mathrm{~cm}$ de altura para o tratamento $1,43 \mathrm{e} 45 \mathrm{~cm}$ para o tratamento 2,52 e $62 \mathrm{~cm}$ para o tratamento 3 e 73 e $78 \mathrm{~cm}$ para o tratamento 4 . Estas alturas médias reais, utilizadas nas análises estatísticas, foram obtidas durante o período de coletas a campo.

O controle da altura do pasto foi feita com novilhos castrados da raça Nelore, com peso vivo inicial médio de $210 \mathrm{~kg}$, sob pastejo com lotação contínua e carga variável, segundo a técnica "put and take" (Mott \& Lucas, 1952). A altura do pasto foi estimada semanalmente, com o auxílio de régua graduada, em 40 pontos de cada unidade experimental. Para a estimativa da altura do pasto, foi considerada a extremidade ou o ponto de curvatura da lâmina da folha mais alta do local de amostragens, a partir do nível do solo.

Os animais iniciaram o pastejo nos piquetes em 18/12/1998. As coletas de dados iniciaram quando a altura do pasto estava próxima à pretendida para os respectivos tratamentos. Assim, elas ocorreram em 01/02, 01/03 e 29/03/1999 e o experimento durou cerca de 95 dias, realizando-se coletas aos 28, 56 e 84 dias.

Para avaliação dos perfilhos, foram coletados ao acaso 30 perfilhos basais em cada piquete, nos quais foram determinados: número de nós, comprimento de entrenós e diâmetro do colmo, sendo os mesmos cortados longitudinalmente para permitir a visualização e medição da altura do meristema apical. Após estas observações, os perfilhos foram secos em estufas de circulação de ar forçado $\left(55^{\circ} \mathrm{C}\right)$, por 72 horas para a obtenção do peso seco dos perfilhos basais. As avaliações foram feitas a cada 28 dias.

R. Bras. Zootec., v.31, n.5, p.1931-1937, 2002
A densidade de perfilhos (basais e aéreos) foi determinada, utilizando-se quadrados de $0,25 \mathrm{~m} \mathrm{x}$ $0,25 \mathrm{~m}$, alocados em cinco pontos ao acaso de cada piquete, nos quais foram feitas contagens do número de perfilhos aéreos e basais.

Foram coletadas 75 folhas por unidade experimental, compostas por um terço de folhas em crescimento, um terço de folhas totalmente expandidas e um terço de folhas maduras, em cinco áreas de $0,25 \times 0,25 \mathrm{~m}$. Procedeu-se à determinação da área foliar das mesmas por intermédio do integralizador de área foliar. Oíndice de área foliar (IAF) foi determinado segundo metodologia sugerida por Peterson (1970).

Os valores estimados das diversas variáveis foram analisados por equações de regressão, testadas pelo teste t, por intermédio do programa SAEG (1993), adotando-se a metodologia de superfície de resposta, a partir do modelo polinomial quadrático, com duas variáveis independentes. O modelo estatístico para análise dos resultados no pasto foi:

$Y_{i j k}=b_{0}+b_{1} A_{i}+b_{2} A_{i}^{2}+b_{3} D_{j}+b_{4} D_{j}^{2}+b_{5} A_{i} D_{j}+e_{i j k}$, em que: $Y_{i j k}=$ características estudadas; $A_{i}=$ efeito da altura i $(\mathrm{cm})(\mathrm{i}=24,26,43,45,52,62,73$ e 78); $\mathrm{D}_{\mathrm{j}}=$ efeito do período de coleta $\mathrm{j}$ (dias) $(\mathrm{j}=28,56,84)$; $\mathrm{b}_{0}=$ constante da regressão; $\mathrm{b}_{1}, \mathrm{~b}_{2}, \mathrm{~b}_{3}, \mathrm{~b}_{4}$ e $\mathrm{b}_{5}=$ coeficientes de regressão; $\mathrm{e}_{\mathrm{ijk}}=$ erro aleatório associado a cada observação $Y_{\mathrm{ijk}}$.

\section{Resultados e Discussão}

Para o número de perfilhos basais, o teste $\mathrm{t}$ revelou efeito linear com relação ao período de coleta $(\mathrm{P}<0,05)$, como mostra a Figura 2. Já a altura do pasto não influenciou o mesmo parâmetro $(\mathrm{P}>0,05)$.

A equação de regressão para número de perfilhos basais (Figura 2) evidenciou queda no número de perfilhos, do início para o final do período de coleta, fato que pode ser explicado em parte pela redução na precipitação pluviométrica, ocorrida com o avanço nos períodos de coletas (Figura 1). As condições ambientais exercem importante influência sobre o perfilhamento e, principalmente, temperatura e intensidade luminosa baixas, e déficit hídrico reduzem a capacidade de perfilhamento, diminuindo a densidade e o peso de perfilhos (Humphreys, 1991).

$\mathrm{O}$ perfilhamento basal não foi influenciado $(\mathrm{P}>0,05)$ pela altura do pasto, concordando com Drudi et al. (1986), em trabalho com capimAndropógon (Andropogon gayanus), no qual, as 


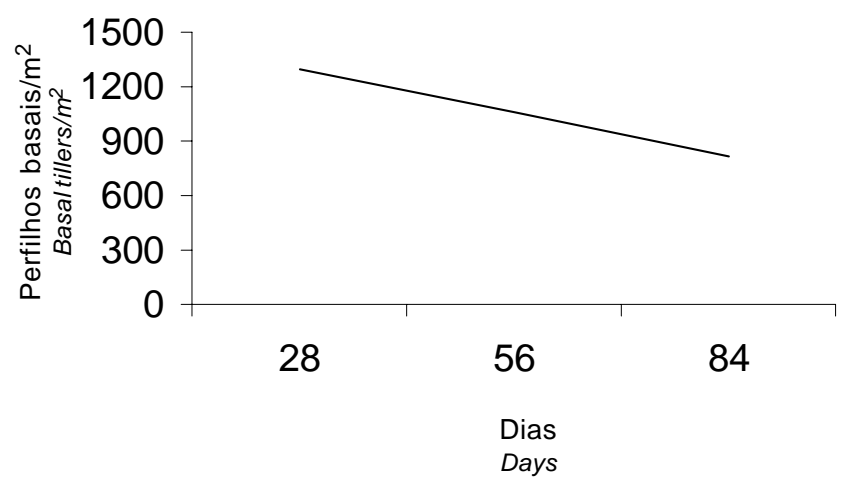

Figura 2 - Estimativas dos números de perfilhos basais $/ \mathrm{m}^{2}$, em função do período de coleta (D), em dias.

Figure 2 - Basal tillers number $/ \mathrm{m}^{2}$ estimates, according to the sampling period $(D)$, in days.

$\hat{y}=1540-8,62143^{*} \mathrm{D} \quad \mathrm{R}^{2}=0,46$

* Significativo pelo teste $t(P<0,05)$.

diferentes alturas de corte não produziram efeito no perfilhamento desta espécie. Considerando a relação existente entre oferta de forragem e altura do pasto, esses resultados estão de acordo com Almeida et al. (2000), que verificaram em estudo com capimelefante anão (Pennisetum purpureum Schum.), que diferentes ofertas de forragem não influenciaram a densidade de perfilhos. No entanto, em Lolium perene sob pastejo contínuo, Penning et al. (1991) observaram maior perfilhamento nas menores alturas do pasto. Em relvados onde ocorre maior cobertura, em função da altura mais elevada do pasto, pode haver redução do perfilhamento por sombreamento (Cecato, 1993).

O número de perfilhos aéreos apresentou comportamento linear e crescente para a altura do pasto $(\mathrm{P}<0,05)$ e linear decrescente para o período de coleta $(\mathrm{P}<0,05)$, conforme Figura 3. Provavelmente, a localização superficial dos meristemas apicais, em posição de fácil acesso aos animais conduziu a eliminação dos mesmos e, conseqüentemente, intensificando-se o perfilhamento lateral da planta. De acordo com Langer (1979), o desenvolvimento das gemas laterais é estimulado, entre outros fatores, pela decapitação do perfilho mãe, cessando a dominância do meristema apical. Também Barbosa et al (1996), observaram que a maior elevação do meristema apical proporcionou maior aparecimento de perfilhos aéreos, em cultivares de Panicum maximum Jacq., devido ao maior desenvolvimento de gemas axilares.

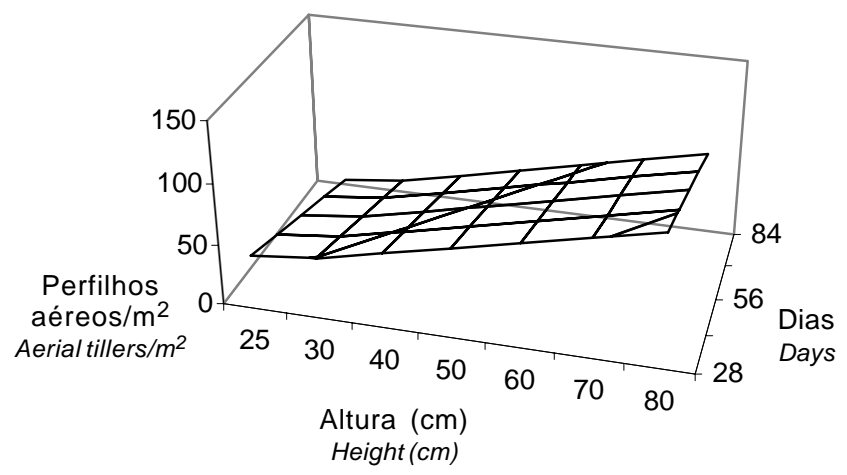

Figura 3 - Estimativas dos números de perfilhos aéreos, em função da altura do pasto $(A), e m \mathrm{~cm}$, e do período de coleta (D), em dias.

Figure 3 - Aerial tillers number estimates, according to the sward height $(A)$, in $\mathrm{cm}$, and the sampling period (D), in days.

$\hat{y}=35,79+1,16 * \mathrm{~A}-0,72 * \mathrm{D} \quad \mathrm{R}^{2}=0,44$

* Significativo pelo teste $t(P<0,05)$.

O número de perfilhos aéreos diminuiu do início para o final do experimento, contrariando resultados observados em experimentos com corte mecânico, onde o avanço na idade da planta proporcionou aumento no número de perfilhos (Herling et al., 1991). De modo geral, a principal forma de perfilhamento do capim-Tanzânia, independente da altura de manejo utilizada e do período de coleta, são os perfilhos basais, apresentando de 800 a 1300 perfilhos $/ \mathrm{m}^{2}$, e não os aéreos, com 30 a 100 perfilhos $/ \mathrm{m}^{2}$, concordando com Barbosa et al.(1996). No entanto, não se pode inferir sobre a importância deste tipo de perfilho para a produção da forrageira, devido à inexistência de trabalhos quantificando a sua contribuição em uma pastagem sob pastejo.

O peso médio de perfilhos basais aumentou linearmente $(\mathrm{P}<0,05)$ com a elevação na altura do pasto (Figura 4).

Os piquetes manejados a alturas maiores apresentaram perfilhos basais mais pesados, devido ao alongamento mais marcante dos entrenós nas plantas maiores e também por apresentarem maiores diâmetros (Figura 5). Segundo Silsbury (1966), o alongamento dos entrenós resulta em aumento no peso do perfilho. Almeida et al. (2000) também verificaram aumento linear no peso de perfilhos, com o aumento na oferta de forragem em capim-elefante anão.

O peso médio de perfilhos basais não apresentou variações $(\mathrm{P}>0,05)$ ao longo do período experimental, provavelmente, devido ao controle de altura realizado

\section{R. Bras. Zootec., v.31, n.5, p.1931-1937, 2002}




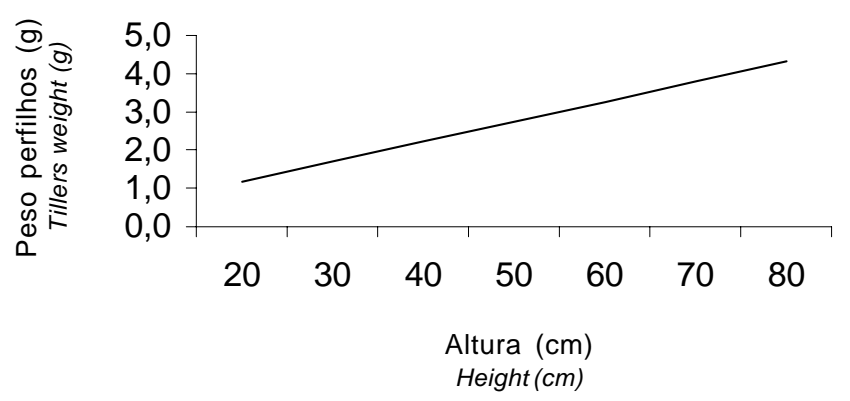

Figura 4 - Estimativas dos pesos de perfilhos basais $(\mathrm{g})$, em função da altura do pasto $(A), e m \mathrm{~cm}$.

Figure 4 - Basal tillers weight $(g)$ estimates, according to the sward height $(A)$, in $\mathrm{cm}$.

$\hat{\mathrm{y}}=0,12+0,052 * \mathrm{~A} \quad \mathrm{R}^{2}=0,70$

* Significativo pelo teste $t(P<0,05)$.

nos respectivos tratamentos, mantendo constante a altura do pasto desde o primeiro período de coleta.

O diâmetro do colmo de perfilhos basais aumentou em função da altura do pasto $(\mathrm{P}<0,05)$ e apresentou comportamento quadrático, com relação ao período de coleta $(\mathrm{P}<0,05)$, apresentando ponto de máximo aos 44 dias de experimento, conforme Figura 5. Os acréscimos no diâmetro de perfilhos, com o aumento da altura do pasto, podem ser explicados, em parte, pela maior possibilidade em expansão de tais perfilhos, devido à utilização de baixas pressões de pastejo nos piquetes manejados mais altos.

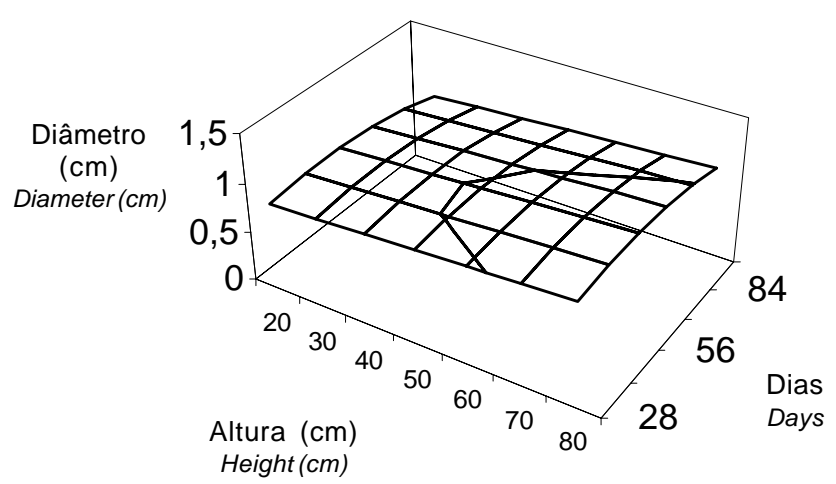

Figura 5 - Estimativas dos diâmetros dos colmos de perfilhos basais $(\mathrm{cm})$, em função da altura do pasto $(A), e m \mathrm{~cm}$, e do período de coleta (D), em dias.

Figure 5 - Stem diameter of basal tillers $(\mathrm{cm})$ estimates, according to the sward height $(A)$, in $\mathrm{cm}$, and the sampling period $(D)$, in days.

$\hat{y}=0,53+0,0026 * A+0,015 * D-0,00017 * D^{2} \quad R^{2}=0,66$

* Significativo pelo teste $\mathrm{t}(\mathrm{P}<0,05)$.

R. Bras. Zootec., v.31, n.5, p.1931-1937, 2002
O número de nós, o comprimento de entrenós, a altura de meristema apical e o índice de área foliar apresentaram comportamento linear $(\mathrm{P}<0,05)$, em relação ao aumento da altura do pasto, e quadrático $(\mathrm{P}<0,05)$, ao longo do período experimental, apresentando os seguintes pontos de mínimo: 55, 55, 58 e 58 dias, respectivamente (Figuras 6, 7, 8 e 9).

O aumento do número de nós por perfilho e do comprimento de entrenós com os aumentos na altura do pasto são alterações morfológicas importantes da planta, que evidenciam a adaptação da planta ao pastejo. Estes resultados concordam com Almeida et al. (2000), que, trabalhando com diferentes ofertas de forragem, verificaram diminuição no número de nós e do comprimento de entrenós, com a redução na oferta de forragem.

Em todas as alturas de manejo, foram observados decréscimos no número de nós e no comprimento de entrenós no segundo período de coleta, aos 56 dias, com posterior aumento destas variáveis aos 84 dias. Este aumento coincide com o início do período reprodutivo da planta, o que pode ter gerado, conseqüentemente, um alongamento dos entrenós, conforme observado por Langer (1979).

O efeito linear e positivo da altura do pasto sobre a elevação do meristema apical sugere mudanças morfológicas nas plantas do relvado, de acordo com o manejo utilizado. A localização de meristemas apicais mais próximos do solo, nos piquetes mantidos em alturas menores, está de acordo com Gomide et

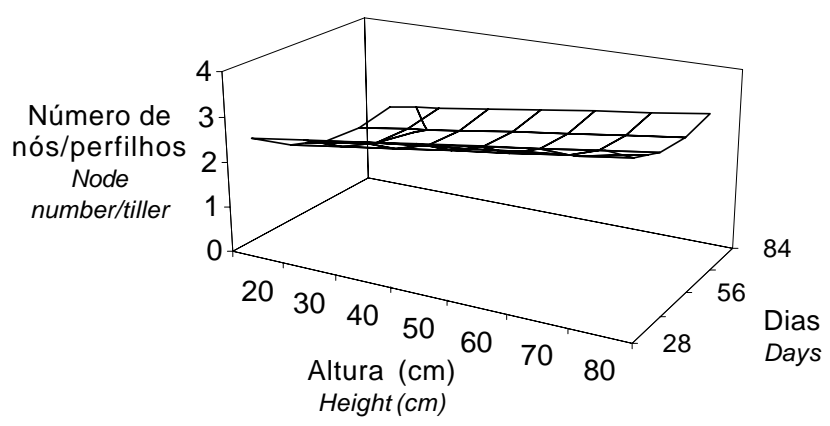

Figura 6 - Estimativas dos números de nós/perfilho basal, em função da altura do pasto $(A)$, em $\mathrm{cm}$, e do período de coleta em dias (D).

Figure 6 - Node number/basal tiller estimates, according to the sward height $(A)$, in $\mathrm{cm}$, and the sampling period (D), in days.

$\hat{y}=5,09+0,017 * A-0,133 * D+0,0012 * D^{2} \ldots R^{2}=0,62$

* Significativo pelo teste $\mathrm{t}(\mathrm{P}<0,05)$. 


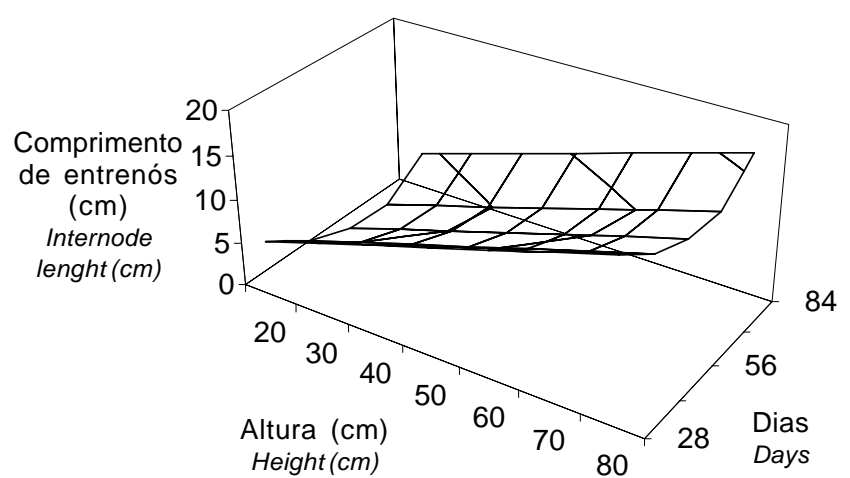

Figura 7 - Estimativas dos comprimentos de entrenós (cm) de perfilhos basais, em função da altura do pasto $(A)$, em $\mathrm{cm}$, e do período de coleta (D), em dias.

Figure 7 - Internode length $(\mathrm{cm})$ estimates of basal tillers, according to the sward height $(A)$, in $\mathrm{cm}$, and the sampling period $(D)$, in days.

$\hat{\mathrm{y}}=19,73+0,196 * \mathrm{~A}-0,83 * \mathrm{D}+0,0075 * \mathrm{D}^{2} \quad R^{2}=0,7$

* Significativo pelo teste $t(P<0,05)$.

al. (1979), que verificaram a elevação do meristema apical, com o aumento da altura de corte.

De forma semelhante ao número de nós e comprimento de entrenós, a altura de meristema apical reduziu no segundo período de coleta e aumentou no período final, nas diferentes alturas de manejo. Provavelmente, a altura média de localização do meristema apical reduziu no segundo período de coleta devido à eliminação dos meristemas situados nos estratos superiores do pasto, que permitem acesso mais fácil aos animais, evidenciando, novamente, a adaptação da planta ao manejo utilizado. Gomide et al. (1979) verificaram que cortes mais baixos em capim-colonião (Panicum maximum) resultaram em redução da altura dos meristemas apicais.

A elevação ocorrida aos 84 dias pode ser explicada em parte como resposta ao início do período reprodutivo, com o alongamento do colmo e elevação dos meristemas apicais, conforme afirmação de Langer (1979).

O IAF aumentou em função da altura do pasto, concordando com Penning et al. (1991), que observaram em Lolium perene sob pastejo contínuo com ovinos, maiores valores de IAF mantendo o pasto mais alto. Zimmer (1999), avaliando os capins-Aruana e Vencedor submetidos a resíduos de pastejo baixo e alto $(3.600$ e $4.500 \mathrm{~kg} /$ ha de MS residual, respectivamente), observou maiores valores de IAF remanescente no tratamento de resíduo de pastejo alto, em todos os períodos de coleta.

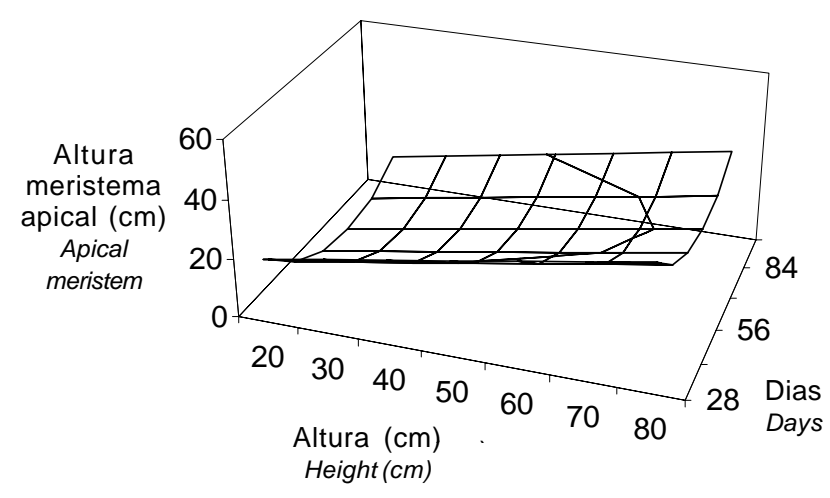

Figura 8 - Estimativas das alturas dos meristemas apicais $(\mathrm{cm})$ em função da altura do pasto em $\mathrm{cm}(\mathrm{A})$ e do período de coleta em dias (D).

Figure 8 - Apical meristem height $(\mathrm{cm})$ estimates, according to the sward height $(A)$, in $\mathrm{cm}$, and the sampling period $(D)$, in days.

$\hat{\mathrm{y}}=72,37+0,34 * \mathrm{~A}-2,71 * \mathrm{D}+0,023 * \mathrm{D}^{2} \quad \mathrm{R}^{2}=0,68$

* Significativo pelo teste $t(P<0,05)$.

Com relação ao período de coleta, observou-se redução nos valores de IAF, aos 56 dias e elevação, aos 84 dias, semelhante ao comportamento observado na altura dos meristemas apicais. A possível explicação para os incrementos no IAF aos 84 dias seria a reconstituição da área foliar a partir dos meristemas apicais remanescentes. Provavelmente,

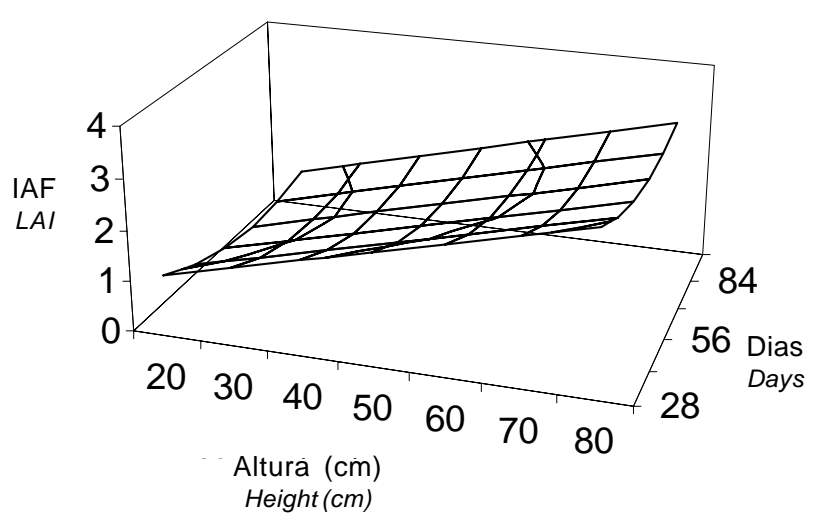

Figura 9 - Estimativas dos índices de área foliar (IAF) em função da altura do pasto em $\mathrm{cm}$ (A) e do período de coleta em dias (D).

Figure 9 - Leaf area index (LAI) estimates, according to the sward height $(A)$, in $\mathrm{cm}$, and the sampling period $(D)$, in days.

$\hat{y}=2,32+0,0338 * A-0,082 * D+0,0007 * D^{2} \quad R^{2}=0,74$

* Significativo pelo teste $t(P<0,05)$. 
a maior eliminação de meristemas apicais no segundo período de coleta favoreceu o perfilhamento e a renovação das folhas, acarretando incrementos no IAF.

De acordo com Humphreys (1966), para $P$. maximum, considera-se a faixa de IAF ótimo ou crítico entre 3 e 5, sendo que, abaixo destes valores, o crescimento é reduzido. No presente trabalho, o IAF oscilou entre 1,2 e 3,2 nas diferentes alturas do pasto e diferentes períodos. Estes índices podem ser considerados altos em comparação àqueles observados nas cultivares Aruana e Vencedor, que foram 0,56 e 0,58 , respectivamente, sendo estes valores a média de três anos consecutivos de avaliação, considerando o período chuvoso e seco (Zimmer,1999).

\section{Conclusões}

A elevação na altura de pastejo produziu plantas com perfilhos basais mais pesados, com maior diâmetro, maior número de nós, maior comprimento de entrenós, maior elevação do meristema apical, maior IAF e maior número de perfilhos aéreos.

$\mathrm{O}$ avanço no período de coleta levou à redução na intensidade do perfilhamento basal e aéreo das plantas.

O número de nós, comprimento de entrenós, altura de meristema apical e IAF reduziram da primeira para a segunda coleta, seguida por elevação no terceiro período.

\section{Literatura Citada}

ALMEIDA, E.X.; MARASCHIN, G.E.; HARTHMANN, O.E.L. et al. Oferta de forragem de capim elefante anão 'Mott' e o rendimento animal. Revista Brasileira de Zootecnia, v.29, n.5, p.1288-1295, 2000.

BARBOSA, M.A.A.; DAMASCENO, J.C.; CECATO, U. Influência da eliminação do meristema apical no aparecimento de perfilhos em quatro cultivares de Panicum maximum Jacq. In: REUNIÃO ANUAL DA SOCIEDADE BRASILEIRA DE ZOOTECNIA, 33., 1996, Fortaleza. Anais... Fortaleza: Sociedade Brasileira de Zootecnia, 1996. p.104-106.

BRISKE, D.D. Developmental morphology and physiology of grasses. In: HUTSCHMIDE, R.K.; STUTHRED, J.W. (Eds.) Grazing management an ecological perspective. 1.ed. Portland: Timber Press, 1991. p.85-108.

BROUGHAM, R.W. Effect of intensity of defoliation on regrowth of pasture. Australian Journal of Agriculture Research, v.7, n.5, p.377-387, 1956.

CECATO, U. Influência da freqüência de corte, níveis e formas de aplicação do nitrogênio sobre a produção, a composição química e algumas características da rebrota do capim Aruana (Panicum maximum Jacq. cv. Aruana). Jaboticabal: Universidade Estadual Paulista, 1993. 112p. Tese (Doutorado em Produção Animal) - Universidade Estadual Paulista, 1993.

COMISSÃO DE FERTILIDADE DO SOLO RS/SC. Recomendações de adubação e calagem para os Estados do Rio Grande do Sul e Santa Catarina. 3.ed. Passo Fundo, 1995. 223p.

R. Bras. Zootec., v.31, n.5, p.1931-1937, 2002
CORRÊA, A.R. Forrageiras: aptidão climática do Estado do Paraná. 1996. In: MONTEIRO, A.L.; MORAES, A.; CORRÊA, E.A.S. et al. (Eds.) Forragicultura no Paraná. 1 ed. Londrina: CPAF, 1996. p.15-22.

DRUDI, A.; FAVORETTO, V.; REIS, R. A. Influência da altura e da frequência de corte sobre algumas características da rebrota do capim-Andropógon. Pesquisa Agropecuária Brasileira, v.21, n.4, p.409-416, 1986.

GOMIDE, J.A.; OBEID, J.A.; RODRIGUES, L.R.A. Fatores morfofiosiológicos de rebrota do capim-colonião (Panicum maximum). Revista Sociedade Brasileira de Zootecnia, v.8, n.4, p.532-561, 1979.

GOMIDE, J.A.; ZAGO, C.P. Crescimento e recuperação do capim colonião após o corte. Revista Brasileira de Zootecnia, v.9, n.2, p.293-305, 1980.

HERLING, V.R.; BRAGA, J.G.; LUZ, P.H.C. et al. Tobiatã, Tanzânia, Mombaça. In: SIMPÓSIO SOBRE MANEJO DA PASTAGEM, 12., 1995, Piracicaba. Anais... Piracicaba: Fundação de Estudos Agrários "Luiz de Queiroz”, 1995. p.21-64.

HUMPHREYS, L.R. Tropical pasture utilization. 1.ed. Australia: Cambridge University Press, 1991. 206p.

LANGER, R.H.M. How grasses grow. 2.ed. London: Edward Arnold, 1979. 66p.

MONTEIRO, A.L.G.; MORAES, A. Fisiologia e morfologia de plantas forrageiras. In: MONTEIRO, A.L.G.; MOARES, A. et al. Forragicultura no Paraná. 1.ed. Londrina: CPAF, 1996. p.75-93.

MOTT, G.O.; LUCAS, H.L. The design, conduct and interpretation of grazing trials on cultived and improved pastures. In: INTERNATIONAL GRASSLAND CONGRESS, 1952, Pensylvania. Proceedings... Pensylvania: State College Press, 1952. p.1380-1385.

NASCIMENTO, M.P.S.B.; NASCIMENTO, H.T.S.; GOMIDE, J.A. Alguns aspectos morfofisiológicos de três gramíneas de clima tropical. Revista Sociedade Brasileira de Zootecnia, v.9, n.1, p.142-158, 1980.

PENNING, P.D.; PARSONS, A.J. Intake and behavior responses by sheep to changes in sward characteristics under continuous stocking. Grass and Forage Science, v.43, n.15, p.15-28, 1991.

PETERSON, R.A. Efeito do corte ou pastoreio sobre as plantas. In: PETERSON, R.A. (Ed.) Fundamentos de manejo de pastagens. 1.ed. São Paulo: Instituto de Zootecnia, 1970. p.37-62.

SILSBURY, J.H. Interrelations in the growth and development of Lolium. II. Tiller number and dry weight at low density. Australian Journal of Agriculture Research, v.17, n.6, p.841-847, 1966.

SISTEMA PARA ANÁLISE ESTATÍSTICAS E GENÉTICAS SAEG. Viçosa, MG: Universidade Federal de Viçosa, 1993.

ZIMMER, A.H. Efeito dos níveis de nitrogênio e resíduos de pastejo sobre a produção, estrutura e qualidade das cultivares Aruana e Vencedor de Panicum maximum Jacq. Jaboticabal: Universidade Estadual Paulista, 1999. 213p. Tese (Doutorado em Zootecnia) - Universidade Estadual Paulista, 1999.
Recebido em: 05/10/01 Aceito em: 13/06/02 